\title{
Determinantes para Cumprimento do Prazo de Projetos do Programa de Aquisição Alimentos - Doação Simultânea em Minas Gerais ${ }^{1}$
}

\author{
Jader Fernandes Cirino² e Silas Vinicio Marini da Silva ${ }^{3}$
}

Resumo: O estudo apontou determinantes que afetaram o cumprimento do prazo, por parte das organizações sociais, sobretudo, associações, dos projetos do PAA-DS no estado de Minas Gerais durante o período 2009-2011. Utilizou-se o modelo de regressão logística e os dados de Cirino et al. (2013). Os resultados apontaram que as variáveis possuir um software de Sistema de Informação Gerencial (SIG), realizar planejamento de produção junto aos agricultores e quantidade de projetos dos quais o principal responsável pela gestão do PAA-DS dentro da organização social participou da elaboração aumentam a probabilidade do cumprimento do referido prazo. Já as variáveis atraso na entrega de produtos por parte dos agricultores e quantidade de projetos dos quais o principal responsável pela gestão do PAA-DS dentro da organização social participou da gestão reduzem as chances de as organizações sociais finalizarem o projeto do PAA-DS dentro do prazo estipulado. Dessa forma, coloca-se a necessidade de políticas públicas de fomento para aquisição e implementação do SIG para a gestão de tais empreendimentos, assim como a capacitação das organizações proponentes no sentido de permitir que as mesmas coloquem em prática as funções administrativas, já que tais funções contribuem para o cumprimento do prazo de projetos do PAA-DS.

Palavras-chaves: Cumprimento do prazo de projetos, programa de aquisição de alimentos, doação simultânea, Minas Gerais.

Abstract: The study presents some determinants that affect the compliance of PAA-
DS projects within the stipulated period of 10 months in Minas Gerais state for the
period between 2009 and 2011. It was used the logistic regression model and the data
was obtained from Cirino et al. (2013). The results showed that the variables have a
Management Information System, have a production planning with farmers and number
of projects of which the main responsible for the management of PAA-DS within the social
1. Data de submissão: 23 de março de 2016. Data de aceite: 19 de fevereiro de 2017.
2. Universidade Federal de Viçosa. Viçosa, Minas Gerais, Brasil. E-mail: jader.irino@ufv.br
3. Universidade Federal de Minas Gerais. Belo Horizonte, Minas Gerais, Brasil. E-mail:
silasvmsilva@gmail.com 
organization participated of the elaboration increase the probability of finishing the project on time. On the other hand, the variables delay in delivery of products by farmers and number of projects of which the main responsible for the management of PAA-DS within the social organization participated in the management reduce the chances of social organizations finish the PAA-DS project within the stipulated time. Thus, there is the need for public policies to encourage the acquisition and implementation of a Management Information System for management of such projects, as well as the empowerment of organizations in order to enable them to implement the practice of administrative functions, as such functions they are linked to finish PAA-DS projects on time.

Key-words: Finish project on time, food Acquisition Program, buy direct ode with simultaneous donation, Minas Gerais.

DOI - http://dx.doi.org/10.1590/1234-56781806-94790550203

Classificação JEL: Q18, M15, M14.

\section{Introdução}

A agricultura familiar é fundamental para a segurança alimentar dos brasileiros, conforme pode ser visualizado a partir dos dados do Censo Agropecuário de 2006 do Instituto Brasileiro de Geografia e Estatística (IBGE). O setor produz $70 \%$ do feijão, $87 \%$ da mandioca, $46 \%$ do milho, $38 \%$ do café, $34 \%$ do arroz, $58 \%$ do leite, $59 \%$ do plantel de suínos, $50 \%$ das aves, $30 \%$ dos bovinos e, ainda, $21 \%$ do trigo consumido no País. Ressalta-se que, apesar de ocuparem em torno de um quarto da área produtiva do País, os 4.367.902 estabelecimentos da agricultura familiar são responsáveis por $38 \%$ do valor da produção agropecuária total do Brasil, ou seja, R\$ 54,4 bilhões. Dessa forma, apesar do cultivo em menor área, os agricultores familiares produzem diversificadas culturas em quantidades expressivas, contribuindo para o aumento da produção animal; além de gerarem emprego e renda no campo. Em 2006, 12,3 milhões de pessoas trabalhavam nesse segmento, totalizando $74,4 \%$ do pessoal ocupado no total dos estabelecimentos agropecuários (IBGE, 2009).

A definição de agricultura familiar de forma a diferenciá-la dos estabelecimentos patronais de produção agropecuária não é trivial, conforme destaca Buainain (2006). A despeito disso, a Lei n. 11.326/2006, disponível em Brasil (2013), define de forma oficial o agricultor familiar como aquele que atende às seguintes características: i) não tem área superior a quatro módulos fiscais ; ii) utiliza mão de obra predominante da própria família nas atividades econômicas da propriedade; iii) tem renda familiar oriunda de atividades econômicas vinculadas ao próprio estabelecimento e iv) dirige seu estabelecimento com sua família. É exatamente essa a definição utilizada no Censo Agropecuário de 2006.

Em razão da relevância da agricultura familiar para a produção e o abastecimento nacional, Andrade Júnior (2009) destaca a importância de políticas destinadas para esse segmento com o objetivo de garantir a segurança alimentar do país assim como a geração de trabalho e renda no campo, bem como o fomento da qualidade de vida dos produtores e seus familiares. Nesse sentido, conforme Bebbington, Abramovay e Chiriboga (2008), como decorrência da organização representativa do grupo de agricultores familiares, colocando em evidência suas reivindicações para a sociedade, teve-se a elaboração de

4. O módulo fiscal representa uma unidade de medida instituída pelo Incra (Instituto Nacional de Colonização e Reforma Agrária) para indicação da extensão mínima das propriedades rurais consideradas áreas produtivas economicamente viáveis, podendo variar de cinco a 110 hectares, conforme o município. Para mais detalhes, consultar Landau et al. (2012). 
políticas públicas para tal segmento. ${ }^{5}$ Nesse contexto, se enquadra o Programa de Aquisição de Alimentos (PAA).

O PAA surgiu como uma forma de promover o desenvolvimento rural por meio do incentivo à agricultura familiar e o combate à insegurança alimentar a partir da distribuição de alimentos produzidos por agricultores familiares para as entidades participantes do programa.

Como forma de melhorar os resultados obtidos, o PAA, segundo MDS (2015), é aplicado em seis modalidades diferentes ${ }^{6}$ que possuem regras e organizações diferenciadas entre si para atender da melhor forma possível os produtores e consumidores. Dentre essas modalidades, está a Doação Simultânea (PAA-DS), que será o objetivo de estudo desse trabalho.

O PAA-DS tem como característica promover a integração entre os agricultores familiares e as entidades que compõem a Rede de Proteção e Promoção Social que, segundo MDS (2015), são: escolas, creches, asilos, hospitais, programas sociais locais, entre outros.

A operacionalização do PAA-DS, via Companhia Nacional de Abastecimento (Conab), ocorre da seguinte forma: as organizações fornecedoras, no caso as associações e cooperativas de agricultores familiares que possuem Declaração de Aptidão ao Pronaf (DAF), elaboram uma proposta de participação a ser avaliada para a Conab. Se aprovada, as organizações emitem uma Cédula de Produto Rural (CPR-Doação) e passam a fornecer os produtos às entidades beneficiadas. Com o decorrer da entrega dos produtos, a Conab disponibiliza os recursos na conta das organizações em um limite de $\mathrm{R} \$ 2.000 .000,00$ por organização/ano, sendo que essas realizam os pagamentos aos agricultores familiares, limitados a R \$ 8.000,00 por estabelecimento de agricul-

5. No Brasil e na América Latina, a dinâmica de criação e implementação de políticas públicas voltadas para o campo é analisada por Biekart (2005), Silva (2002) e Reardon, Berdegué e Escobar (2001).

6. Além da modalidade Doação Simultânea, há as modalidades: Compra Direta, Apoio à Formação de Estoques, Incentivo à Produção e ao Consumo de Leite, Compra Institucional e Aquisição de Sementes. tura familiar/ano. Também fica a cargo da Conab a fiscalização das atividades das organizações no correr do projeto, assim como a precificação dos produtos, que é feita a partir do estudo de preços praticados nos mercados locais (CONAB, 2015).

Sobre o PAA, estudos ${ }^{7}$ têm apontado o programa como importante mecanismo para a melhoria dos preços pagos aos agricultores familiares envolvidos, assim como para a articulação dos mercados locais. Dessa forma, o programa estaria contribuindo para a geração de renda e emprego no campo. Adicionalmente, verificam-se ganhos significativos em termos de bem-estar e saúde das instituições atendidas pelo programa em função de maior disponibilidade e qualidade de produtos da agricultura familiar para o consumo das mesmas. Entretanto, tais trabalhos também apontam falhas no programa como atrasos nos prazos de entrega e no cronograma de desembolsos, assim como a necessidade de gestão mais eficiente dos projetos desde a elaboração até a consecução.

Dessa forma, no intuito de analisar a gestão e o monitoramento de projetos vinculados ao PAA-DS, a fim de verificar possíveis falhas e apresentar soluções para o acompanhamento e cumprimento do prazo de tais projetos, surge o problema de pesquisa deste trabalho: quais os determinantes que afetaram o cumprimento dos prazos dos projetos do PAA-DS pelas organizações sociais de agricultores familiares no estado de Minas Gerais no período 2009-2011?

A escolha de Minas Gerais ocorreu pela importância da agricultura familiar no estado, onde dos cerca de 500 mil estabelecimentos rurais, $384 \mathrm{mil}$ são da agricultura familiar. Em termos nacionais, Minas Gerais possui cerca de $10 \%$ dos estabelecimentos familiares produtivos do Brasil, ficando atrás apenas da Bahia, com 15\% (IBGE, 2009).

Ao analisar aspectos ligados à condução do PAA a partir de informações referentes ao estado de Minas Gerais como um todo, o estudo contribui para a literatura sobre o tema, uma vez que

7. Rocha, Cerqueira e Coelho (2007), Andrade Júnior (2009), Vieira e Grossi (2010), Almeida, Ferrante e Paulillo (2010), Santos et al. (2012), Cirino et al. (2014) e Cirino et al. (2015). 
a maioria dos trabalhos tem se limitado a estudos de caso de um município ou região, em razão da dificuldade de levantamento de dados para uma área geográfica mais abrangente. Pelo mesmo motivo, poucos também são os estudos que envolvem métodos quantitativos para a análise do programa em questão ${ }^{8}$, aspecto que o presente estudo aborda ao utilizar um modelo de regressão logística para analisar a probabilidade do cumprimento de projetos do PAA-DS dentro do prazo estipulado de 10 meses em função das características das organizações sociais envolvidas, assim como do processo de gestão de tais projetos por parte dessas organizações.

Portanto, o estudo teve como objetivo geral analisar quais variáveis tiveram impacto sobre a probabilidade de cumprimento dos prazos dos projetos de PAA-DS pelas organizações sociais participantes do programa no estado de Minas Gerais. Especificamente, procurou-se: a) verificar se as funções administrativas de Planejamento, Organização, Direção e Controle (PODC) influenciaram na probabilidade de as organizações sociais cumprirem os projetos no prazo e b) determinar se a existência de um programa de Sistema de Informação Gerencial (SIG) foi um fator importante para o cumprimento dos prazos de projetos do PAA-DS.

\section{Gerenciamento de projetos do PAA-DS}

Projeto é um empreendimento temporário conduzido de maneira progressiva, visando à criação de um produto ou serviço único. Nesse sentido, um projeto é único e não repetitivo, formalmente organizado, de duração determinada, congregando e aplicando recursos de forma a alcançar objetivos estabelecidos anteriormente, gerando resultados satisfatórios para um público definido (PMI, 2013).

Para o caso do PAA-DS, podem-se relacionar as características de um projeto descritas anteriormente. Em relação à primeira, observa-se que

8. Magalhães e Soares (2007), Oliveira (2011) e Sobreira (2014) têm estudos dessa natureza. dois projetos PAA-DS em duas regiões distintas obterão resultados diferentes, caracterizando tais experiências como únicas e não repetitivas. Tais projetos são formalmente organizados, já que precisam ser previamente elaborados e submetidos à Conab. Têm duração limitada, já que são previstos para 10 meses, encerrando-se no fim desse período. Por fim, projetos PAA-DS apresentam objetivos específicos, visando alcançar objetivos estratégicos das organizações proponentes. Sobre tal aspecto, destaca-se que tais propostas devem ser elaboradas e executadas de acordo e buscando atender aos interesses dos participantes e associados das associações e cooperativas envolvidas.

De extrema importância no contexto de projetos, tem-se o conceito de gerenciamento deles, definido pelo PMI (2013) como a aplicação de conhecimentos, ferramentas e técnicas voltadas para as atividades do projeto, com a finalidade de atender às demandas e expectativas dos interessados. No caso do PAA-DS, o gerenciamento de um projeto deve ter como foco estratégias para beneficiar os próprios associados, que no caso são trabalhadores da agricultura familiar. Dessa forma, a gestão do PAA-DS consiste em administrar o projeto, utilizando as funções administrativas de Planejamento, Organização, Direção e Controle (PODC) adaptados à realidade da cooperativa/associação. Tais funções são norteadas pelos objetivos declarados no estatuto social da organização proponente e pelos propósitos estabelecidos no projeto PAA-DS.

Iniciando pela função planejamento, ela consiste em um processo administrativo no qual são estabelecidas metas ou objetivos organizacionais, assim como os meios mais adequados para atingi-los conforme os recursos disponíveis (LACOMBE e HEILBORN, 2008). É tida como a primeira função administrativa devido à sua tamanha importância por envolver a solução de problemas e a tomada de decisões não só quanto às alternativas futuras, mas também às alternativas do presente.

Nas cooperativas e associações, seus valores e metas são estabelecidos de acordo com o perfil social, econômico e produtivo de seus associados, 
tendo por intermédio uma organização associativista que possui os princípios da autogestão, autoajuda, autorresponsabilidade e autoadministração, como agentes reguladores. Portanto, deve-se adaptar o modelo de planejamento estratégico às suas características, organizando os seus associados para que, em conjunto, possam, a partir de debates, levantar os problemas e definir objetivos que pretendem atingir. Esses últimos se transformam em objetivos sociais da cooperativa/associação que passa a estabelecer estratégias e planejar propósitos para alcançá-los (EDUCOOP, 2013).

Nesse sentido, o processo de planejamento deve seguir as características próprias de cada organização. A natureza, o porte, o estilo de gestão e a cultura organizacional influenciarão o desenvolvimento desse tipo de atividade e deverão ser levados em consideração.

No que tange à função organização, Lacombe e Heilborn (2008) a definem como o processo de identificar, dividir e alocar o trabalho, definindo responsabilidades e as relações entre os grupos, visando à eficácia do processo para atingir os objetivos propostos. No mesmo sentido, Tenório (2000) destacou a importância de definir quem toma as decisões e sobre quais assuntos, assim como quem deve acompanhar e controlar cada atividade.

A função organização nas cooperativas e associações pode ser estabelecida por meio de vários instrumentos, destacando-se: os estatutos, os regimentos internos, os organogramas e os manuais de rotinas e procedimentos, cabendo maiores explicações sobre os dois primeiros.

Estatuto é o documento legal que determina a missão da organização, descrevendo cada cargo, suas competências e atribuições, além do processo de eleição e mecanismos de tomada de decisão. Regimento interno é o instrumento que visa orientar, padronizar e avaliar o comportamento operacional dos empregados e participantes da associação/cooperativa, bem como integrar as diferentes atividades (EDUCOOP, 2013).

Passando para a função direção, com base em Tenório (2000), pode-se defini-la como aquela que procura garantir a execução das ações nas organizações, fazendo os envolvidos se empenharem ao máximo e utilizarem os recursos disponíveis de forma eficaz.

Para o caso das associações e cooperativas, a fim de que as atividades distribuídas entre os seus membros sejam cumpridas de forma satisfatória, é necessário que seja trabalhada a motivação das pessoas envolvidas, levando-as a assumir suas responsabilidades e cumprir suas atribuições. Conforme destaca Educoop (2013), em tais organizações a função de direção deve ser conduzida de maneira democrática, envolvendo todos os associados no processo decisório.

Depois de definidos os objetivos a serem seguidos (planejamento), estabelecer as equipes que realizarão as atividades (organização) e coordenar, liderar e motivar a equipe (direção), tem-se a fase de análise e avaliação dos resultados que estão sendo alcançados pelo grupo, caracterizando a função controle. Conforme Tenório (2000), esta última tem o objetivo de identificar possíveis desacordos com as metas traçadas pela função planejamento para promover a correção desses, com o intuito de obter, assim, os melhores resultados. De acordo com Educoop (2013), três características devem estar presentes no momento da adoção de medidas corretivas dentro de uma associação ou cooperativa, a saber: precisão, rapidez e adaptabilidade.

Destaca-se, ainda, que a função controle é realizada de acordo com critérios preestabelecidos, tendo por base uma sequência lógica que possibilite a identificação de problemas não detectados na fase de planejamento.

A ocorrência periódica de reuniões para a apresentação e discussão de aspectos referentes ao monitoramento e gerenciamento de propostas do PAA-DS é fundamental para a realização das funções administrativas dentro das organizações proponentes.

Outro ponto importante a destacar é o possível papel do Sistema de Informação Gerencial (SIG) na gestão de projetos do PAA-DS.

Formalmente, o SIG pode ser definido como o "processo de transformação dos dados em informações que são utilizadas na estrutura decisória da empresa, proporcionando, ainda, 
a sustentação administrativa para otimizar os resultados esperados" (OLIVEIRA, 2009, p. 26). Esse autor apontou que o referido sistema tem como objetivo oferecer informações necessárias aos executivos, a fim de que eles possam alcançar resultados e metas preestabelecidas.

As principais dificuldades defrontadas pelas cooperativas/associações que não dispõem de SIG adequado são apontadas por Educoop (2013), conforme segue: i) impossibilidade de participar de licitações por falta de livros obrigatórios, comprovantes de subscrição e integralização de quotas partes; ii) falta de controle adequado de receitas e despesas; iii) diretores de tais organizações sem condições de planejar e gerenciar estas últimas, em razão da inexistência de informações ou da falta de confiabilidade destas; iv) colaboradores desprovidos de instrumentos que ajudem nas suas atividades desenvolvidas dentro das organizações e v) contabilidade geralmente não refletindo a realidade da associação ou cooperativa.

Dessa forma, acredita-se que, com a implantação do SIG, além de ser possível minimizar todos os problemas descritos, haveria maior eficiência na gestão da associação/cooperativa, permitindo que essas entidades pudessem dedicar maior tempo à prospecção de novos associados, clientes, parceiros e projetos, como os do PAA-DS, alcançando, dessa forma, melhores resultados.

\section{Metodologia}

\subsection{Fonte de dados}

Os dados utilizados nesta pesquisa foram obtidos a partir de Cirino et al. (2013). A população de interesse do referido estudo foi constituída por 247 organizações no estado de Minas Gerais que acessaram o PAA-DS no período 2009-2011.

Com base em informações da Conab e de mais 500 contatos de organizações cedidos pela Organização Não Governamental Associação dos Educadores Cooperativistas do Brasil (ONG Educoop), Cirino et al. (2013) obtiveram uma amostra de 117 respondentes, os quais foram identificados como o principal responsável pela gestão de projetos do PAA-DS dentro da organização proponente. Como, em muitos casos, o entrevistado estava envolvido com a gestão de projetos do PAA-DS em mais de uma organização social, os dados apresentados referem-se a mais de 117 organizações, conferindo a estes maior representatividade.

Os respondentes foram constituídos por representantes legais das organizações proponentes, técnicos de diversas áreas do conhecimento, além de técnicos extensionistas lotados em instituições parceiras como prefeituras, Empresa de Assistência Técnica e Extensão Rural (Emater), Conselho Municipal de Desenvolvimento Rural Sustentável (CMDRS), entre outros, que estiveram diretamente ligados à gestão de projetos do PAA-DS nas organizações sociais.

Em relação à representatividade da amostra em termos de abrangência de municípios em todas as mesorregiões mineiras, tem-se a Figura 1, que mostra a distribuição das cidades desses entrevistados, em que as cores mais escuras representam as regiões mais citadas e, de forma gradual, cores mais claras, as menos recorrentes. Os resultados da amostra estão de acordo com a representatividade do PAA, em todas as suas modalidades, no estado de Minas Gerais, conforme pode ser visualizado, comparando-se a Figura 1 com a Figura 2.

Analisando a Figura 2, que ilustra a representatividade do PAA, em todas as suas modalidades, no estado de Minas Gerais, ao longo dos anos 2009, 2010 e 2011, percebe-se maior presença do programa em todas as mesorregiões do estado, principalmente no norte de Minas, Jequitinhonha, Vale do Mucuri, Vale do Rio Doce, Zona da Mata e sul/sudoeste de Minas.

Ao relacionar as informações da Figura 1 com as da Figura 2, percebe-se que as regiões mais citadas pelos respondentes coincidem com aquelas que mais aumentaram a sua representatividade em termos de acesso ao PAA em Minas Gerais. Da mesma forma, as mesorregiões que, ao longo dos anos, tiveram menor representatividade em termos de participação do PAA em Minas Gerais, coincidem com aquelas menos citadas pelos respondentes, que são Triângulo Mineiro, oeste de Minas e Campo das Vertentes. 
Figura 1. Localização dos municípios, por mesorregiões de Minas Gerais, dos responsáveis pelo gerenciamento do PAA-DS

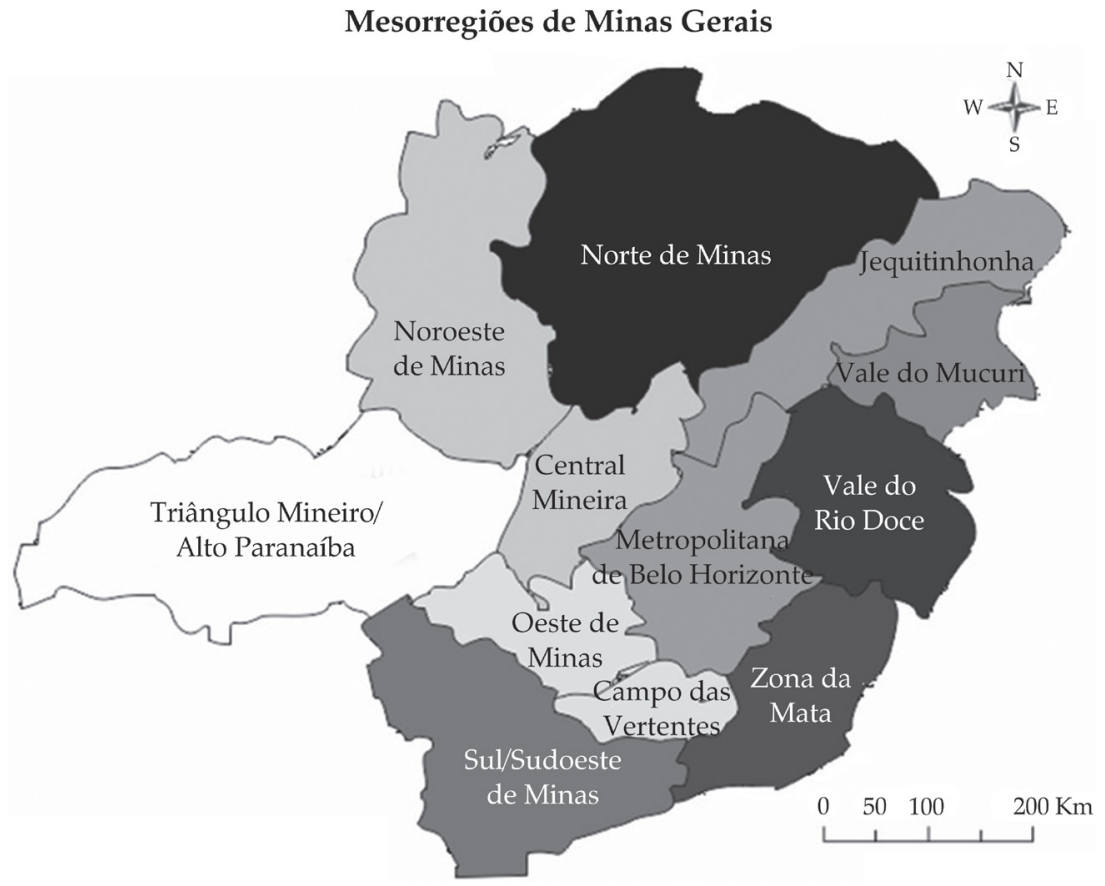

Fonte: Resultados da pesquisa e IBGE (2013).

Figura 2. Evolução ao longo dos anos da representatividade do PAA no estado de Minas Gerais, 2009-2011

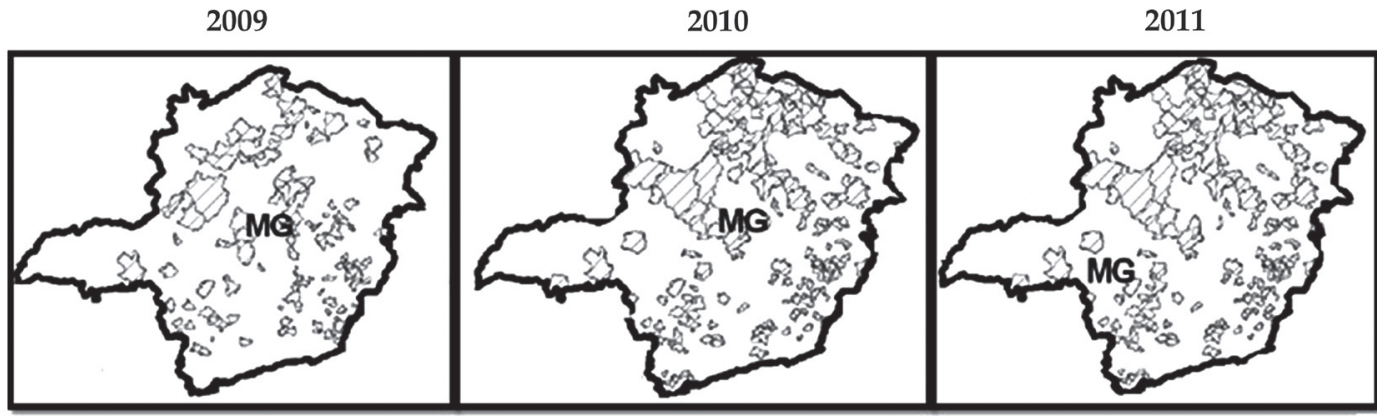

VZ7 Atuação do PAA

Fonte: Conab, 2013. 
3.2. Modelo de regressão logística para análise da probabilidade do cumprimento do prazo de projetos do PAA-DS por parte das organizações proponentes

Para obter os determinantes do cumprimento do prazo de projetos do PAA-DS pelas organizações sociais, foi utilizado o modelo de regressão logística ou modelo logit, cuja descrição apresentada baseia-se em Gujarati e Porter (2008) e Wooldridge (2011).

O modelo logit consiste em um modelo probabilístico que utiliza a função de distribuição logística acumulada que aproxima assintoticamente de 0 à medida que $Z_{i}$ tende $\mathrm{a}-\infty$ e de 1 à medida que $Z_{i}$ tende a $+\infty$. A probabilidade em tal modelo é dada pela seguinte equação:

$$
P_{i}=P\left(Y_{i}=1\right)=F\left(X_{i} \beta\right)=\frac{1}{1+e^{-\left(X_{i}\right)}}
$$

Em que $P_{i}$ representa a probabilidade da organização social $i$ cumprir o projeto do PAA-DS no prazo de 10 meses $\left(Y_{i}=1\right) ; X_{i} \beta$ é um índice que representa as características de gestão de tais projetos por parte das organizações sociais; ${ }^{9} i$, cada um dos respondentes que compõem o total de observações da amostra utilizada; e "e", a base dos logaritmos neperianos.

De forma análoga, a probabilidade da organização social $i$ não cumprir o projeto do PAA-DS no prazo de 10 meses $\left(Y_{i}=0\right)$ é dada por:

$$
1-P_{i}=\frac{1}{1+e^{X_{\beta}}}
$$

Dividindo (1) por (2), tem-se:

$$
\frac{P_{i}}{1-P_{i}}=\frac{1+e^{X_{i} \beta}}{1+e^{-X_{i} \beta}}=e^{X_{i} \beta}
$$

9. Esse índice nada mais é do que a regressão individual para cada respondente considerando-se as variáveis explicativas que foram incluídas no modelo, ou seja, $X_{i} \beta=\beta_{0}+\beta_{1} X_{1 i}+$ ... $+\beta_{\mathrm{k}} X_{k i}$ em que os bs são os parâmetros a serem estimados e os $\mathrm{Xs}$, as variáveis independentes consideradas.
Pode-se observar que $\frac{P_{i}}{1-P_{i}}$ é a razão de chances do evento $Y_{i}=1$ acontecer, ou seja, o cumprimento dos projetos de PAA-DS dentro do prazo.

Aplicando logaritmo natural em (3), obtêm-se:

$$
L_{i}=\ln \left(\frac{P_{i}}{1-P_{i}}\right)=X_{i} \beta
$$

Assim, $L_{i}$ é o logaritmo da razão de chances, denominado logit, que é linear tanto em $X_{i}$ quanto nos parâmetros. Dessa forma, o modelo estimado foi o seguinte:

$$
\begin{aligned}
& L_{i}=\beta_{0}+\beta_{1} \text { Soft }_{i}+\beta_{2} \text { Atraso }_{i}+\beta_{3} \text { Elab }_{i}+ \\
& +\beta_{4} \text { Gestão }_{i}+\beta_{5} \text { Planejamento }_{i}+ \\
& +\beta_{6} D M 1_{i}+\beta_{7} D M 2_{i}+\beta_{8} D M 3_{i}+ \\
& +\beta_{9} D M 4_{i}+\beta_{10} D M 5_{i}+\varepsilon_{i}
\end{aligned}
$$

Em que: $L$ é a variável dependente binária, assumindo o valor 1 para as organizações sociais que conseguem cumprir o projeto do PAA-DS dentro do prazo estipulado e 0, caso contrário; Soft, variável dummy que indica a utilização de um software específico de SIG para a gestão do projeto do PAA-DS pela organização social que assume o valor 1 para as entidades que utilizaram tal programa e 0, caso contrário; Atraso, variável dummy que diz respeito à ocorrência de atrasos na entrega dos alimentos por parte dos agricultores familiares apresentando o valor 1 para as organizações que tiveram registros de atrasos e 0 , caso contrário; Elab e Gestão são, respectivamente, variáveis que quantificam o número de projetos do PAA-DS dos quais os responsáveis pelo gerenciamento de tais projetos dentro das organizações sociais participaram da elaboração e gerenciamento; Planejamento é uma variável dummy que explicita se houve planejamento de produção junto aos agricultores familiares envolvidos nos projetos do PAA-DS, assumindo o valor 1 para as entidades que realizaram o planejamento e 0, caso contrário; DM1,DM2, DM3, DM4 e DM5 são dummies de localização que assumem o valor 1 para as seguintes regiões ou conjunto de regiões, respectivamente: norte de Minas e Vale do Jequitinhonha e Mucuri; Vale do Rio Doce; região 
central mineira e região metropolitana; Zona da Mata; região sul e sudeste, e 0 para o grupo base, que inclui as regiões de Campo de Vertentes, noroeste de Minas, oeste de Minas e Triângulo Mineiro e Alto Paranaíba; $\beta_{l}(1=0$ a 10) são os parâmetros a serem estimados; e $\varepsilon$ é o termo de erro aleatório.

Destaca-se que as variáveis explicativas foram escolhidas com base em estudos relacionados à operacionalização e gerenciamento do PAA tais como Cirino et al. (2014) e Educoop (2013). Quanto à variável dependente, uma vez que ela é discreta, ou seja, assume apenas valores 0 ou 1, a equação (5) foi estimada pelo método da Máxima Verossimilhança ${ }^{10}$.

Uma das aplicações do modelo logit é a possibilidade de se obter o efeito marginal das variáveis explicativas sobre a variável dependente, que no estudo refere-se à probabilidade de as organizações sociais cumprirem o prazo estipulado para a execução de projetos do PAA-DS. Para as variáveis explicativas quantitativas (contínuas), esse efeito é calculado da seguinte forma:

$$
\begin{aligned}
\frac{\partial P_{i}}{\partial X_{k i}} & =\frac{\left(1+e^{-\left(X_{i} \beta\right)}\right) \cdot(0)-(1) \cdot\left(e^{-\left(X_{\beta} \beta\right)} \cdot-\beta_{k}\right)}{\left(1+e^{-\left(X_{i} \beta\right)}\right)^{2}} \\
\frac{\partial P_{i}}{\partial X_{k i}} & =\frac{\beta_{k}\left(e^{-\left(X_{i} \beta\right)}\right)}{\left(1+e^{-\left(X_{i} \beta\right)}\right)^{2}} \\
\frac{\partial P_{i}}{\partial X_{k i}} & =\beta_{k} \cdot \frac{1}{\left(1+e^{-\left(X_{i} \beta\right)}\right)} \frac{\left(e^{-\left(X_{\beta} \beta\right)}\right)}{\left(1+e^{-\left(X_{\beta} \beta\right)}\right)^{2}}
\end{aligned}
$$

Observando que o segundo termo à direita da expressão (6) é a probabilidade de as organizações sociais conseguiram cumprir o projeto do PAA-DS dentro do prazo estipulado $\left(P_{i}\right)$ e o terceiro, a probabilidade de não aceitar o referido pagamento $\left(1-P_{i}\right)$, tem-se que:

$$
\frac{\partial P_{i}}{\partial X_{k i}}=\beta_{k} \cdot P_{i}\left(1-P_{i}\right)
$$

Dessa forma, a equação (7) representa a variação, em pontos percentuais, da variável

10. Para mais detalhes sobre o método, consultar Cameron e Trivedi (2005). dependente, dada uma variação em qualquer variável dependente contínua, mantida as demais constantes.

Com relação aos efeitos marginais de variáveis binárias, o efeito marginal é calculado da seguinte forma:

$$
E M_{X k}=P\left[Y_{i}=1 \mid X_{k i}=1\right]-P\left[Y_{i}=1 \mid X_{k i}=0\right]
$$

Em que $E M_{X k}$ representa o efeito marginal da variável $X_{k}$ sobre a variável dependente. No estudo, tal efeito indica o impacto relacionado ao fato de a variável qualitativa assumir o valor um, em pontos percentuais, sobre a probabilidade de uma organização social cumprir o prazo dos projetos do PAA-DS no período estipulado, mantidas as demais variáveis constantes.

Como no modelo logit os efeitos marginais dependem de $P_{i}$ que, por sua vez, é uma função das variáveis explicativas do modelo, todos os efeitos marginais foram calculados no ponto médio da amostra, ou seja, considerando os valores médios de tais variáveis.

\section{Resultados e discussão}

\subsection{Gerenciamento de projetos vinculados ao PAA-DS por parte das organizações sociais}

Esta subseção analisa a gestão e o monitoramento, por parte das organizações sociais, de projetos vinculados ao PAA-DS com o intuito de verificar as características desse processo. Um primeiro ponto a levantar é a compreensão de como os respondentes controlam o andamento dos projetos supracitados. Em $46 \%$ das respostas, os meios mais utilizados são as planilhas eletrônicas, seguidos de $27 \%$ que utilizam o preenchimento manual de talóes ou formulários, $22 \%$ que possuem sistema de gestão próprio para o PAA-DS e $5 \%$ que citaram outros instrumentos. Segundo os entrevistados, conforme Figura 3, as principais vantagens para se utilizar tais métodos são o baixo custo e a facilidade de inserir os dados do projeto. 
Figura 3. Principais vantagens dos instrumentos gerenciais utilizados pelos respondentes, em termos de porcentagem das respostas totais, Minas Gerais, 2009-2011

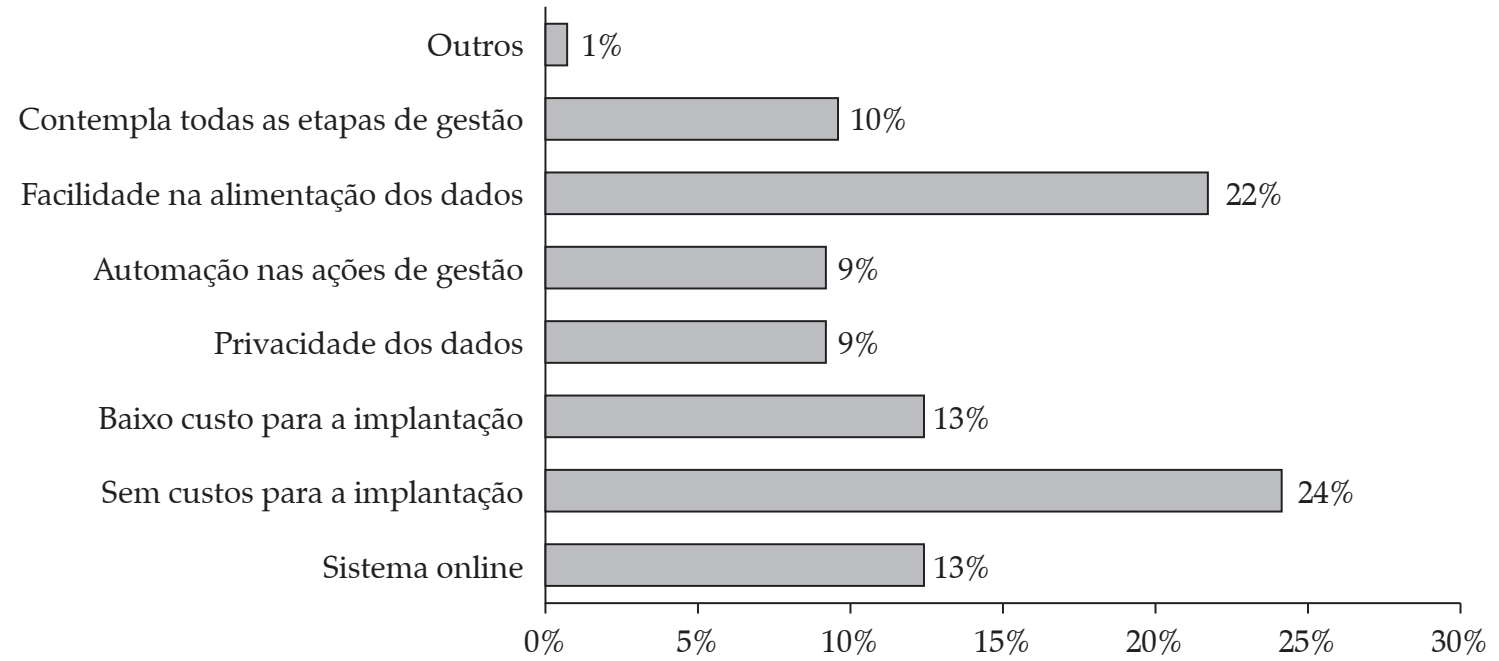

Fonte: Resultados da pesquisa.

De acordo com Educoop (2013), a utilização de talões e formulários pré-impressos na gestão do PAA-DS se dá pela facilidade de visualização por parte dos agricultores familiares, os quais têm dificuldade para entender os dados inseridos em outros instrumentos gerenciais.

Quanto às desvantagens dos instrumentos gerenciais citados anteriormente, os respondentes informaram que os maiores problemas dos mesmos são não contemplar todas as etapas do gerenciamento dos projetos, dificuldade no lançamento dos dados, sistema off-line e falta de automação nas ações de gestão (Figura 4).

Nesse ponto, cabe destacar que os referidos problemas poderiam ser eliminados ou bastante minimizados com a introdução de um SIG capaz de agregar, em um só programa, todas as etapas de gestão do PAA-DS. Tal afirmação é cor-

Figura 4. Principais desvantagens dos instrumentos gerenciais utilizados pelos respondentes, em termos de porcentagem das respostas totais, Minas Gerais, 2009-2011

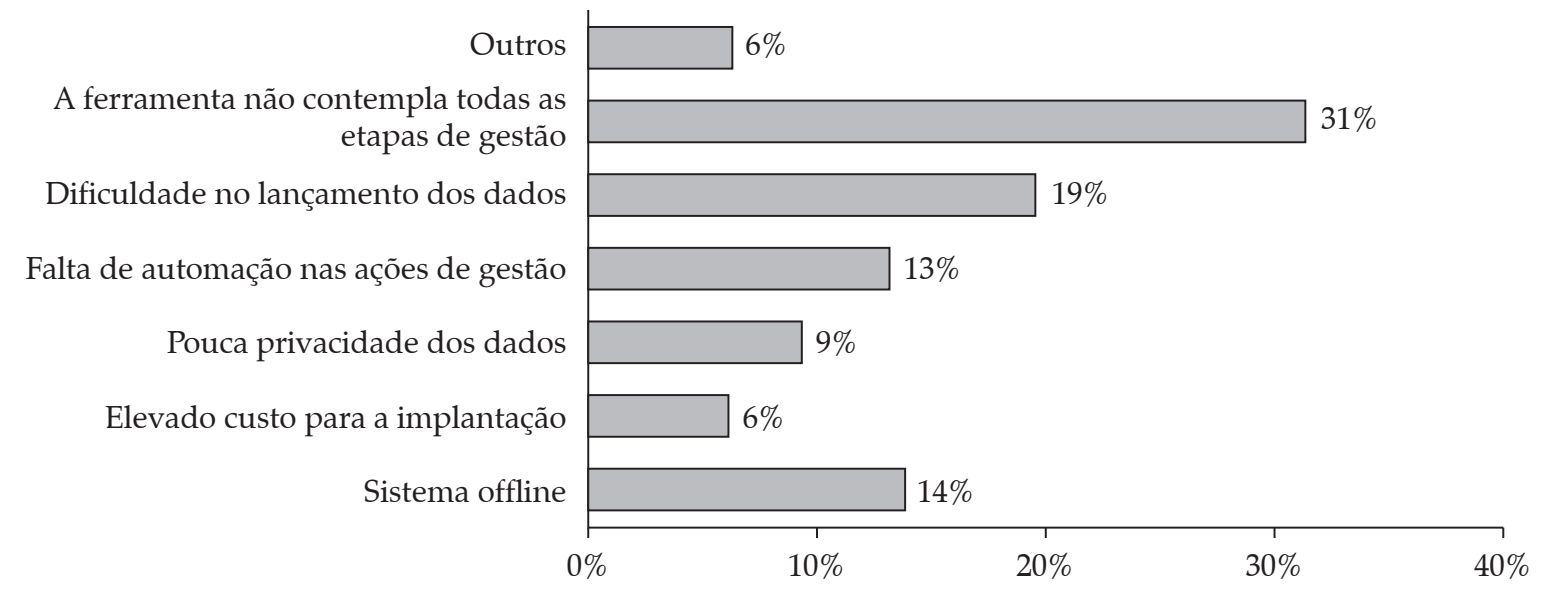

Fonte: Resultados da pesquisa. 
roborada pelos próprios responsáveis pela gestão dos projetos dentro das organizações sociais, uma vez que $75 \%$ deles relataram haver a necessidade de utilizar programa específico para a gestão e a prestação de contas do projeto PAA-DS. No entanto, observa-se que, na prática, as organizações não têm utilizado o SIG, uma vez que o mesmo não aparece como um dos principais instrumentos gerenciais utilizados.

Sobre esse assunto, Ghizelini (2010) relata a importância de se aprimorar os métodos de gerenciamento e operacionalização do PAA, visto que muitas associações têm dificuldade para digitalizar e informatizar os dados. No mesmo sentido, Alves et al. (2011) destacam, em sua pesquisa para os territórios da cidadania de Minas Gerais e Bahia, que o gerenciamento do projeto é apontado como uma das principais deficiências das organizações proponentes frente ao PAA.

Entretanto, 66\% das organizações revelaram não ter recursos financeiros para o desenvolvimento e implantação de tal software. Esse resultado está relacionado à dificuldade financeira que muitas associações e cooperativas enfrentam. Tal informação é comprovada por Buainain (2006), que relata que grande parcela dos agricultores familiares inseridos no mercado apresenta forte incerteza, absorvendo os riscos da produção e do mercado, sendo que a maioria tem muitas dificuldades para se capitalizar, realizar investimentos sustentáveis e levar adiante projetos inovadores. Sobre esse ponto é importante destacar que como tais agricultores são os associados das organizações proponentes, sendo que dos primeiros originam-se a maior fonte dos recursos financeiros para as despesas operacionais das segundas (Figura 5), a falta de capacidade de custeio e investimento dos agricultores familiares reflete nas associações/cooperativas. No mesmo sentido, Grisa et al. (2011) afirmam que a gestão do PAA requer quantidade considerável de recursos humanos, materiais e financeiros, os quais não estão presentes na maioria das organizações sociais. Dessa forma, os autores concluem que a ausência de tais recursos se agrava à medida que o nível de pobreza dos associados se acentua.

Sobre o planejamento dentro das organizações sociais, o qual impacta em todas as atividades das mesmas, incluindo a execução de projetos do PAA-DS, Educoop (2013) ressalta que a realização de tal técnica a curto, médio e longo prazo é fundamental para o desenvolvimento social e empresarial das associações e cooperativas. No entanto, quando os respondentes foram questionados se é realizado planejamento das ações da organização, $22 \%$ das respostas indicam que os gestores conhecem os recursos disponíveis e que o planejamento, segundo $20 \%$ das organizações é feito em termos de curto prazo, com execução em até um ano. Vale ressaltar que 13\% das

Figura 5. Origem dos recursos para pagar as despesas de contrapartida administrativa das organizações proponentes, em termos de porcentagem das respostas totais, Minas Gerais, 2009-2011

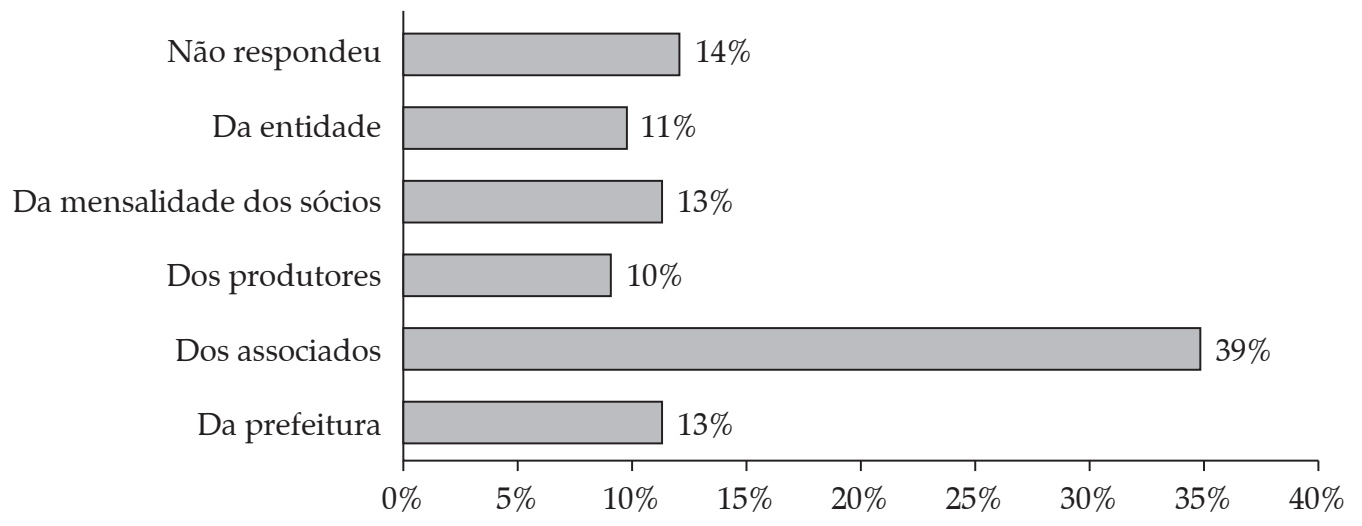

Fonte: Resultados da pesquisa. 
organizações não possuem plano de gestão definido e apenas $7 \%$ e $2 \%$ realizam planejamento de médio e longo prazo, respectivamente. Nesse ponto é importante salientar a vulnerabilidade a que elas estão sujeitas em virtude da falta de planejamento, visto que qualquer organização que deseja ter sucesso deve ajustar seu perfil e se planejar para possíveis mudanças de mercado e conjuntura.

\subsection{Análise descritiva}

Passando para a análise descritiva das variáveis estudadas, observou-se que, em relação ao tipo de organização que acessou o PAA-DS em Minas Gerais no período 2009-2011, a maioria foi de associações, sendo essas citadas em 93\% dos questionários. Esse cenário é justificado pela obrigatoriedade de constituição de uma organização coletiva formal para acesso ao PAA-DS via Conab e pela facilidade de formação de associações em relação às cooperativas. Conforme Araújo, Tolentino e Theóphilo (2009), a exigência de que os produtores estejam em organizações coletivas para terem acesso a programas como o PAA incentiva o aumento desse número de instituições. Nesse contexto, as associações nem sempre são formadas para atenderem às necessidades de seus associados, mas por enfrentarem menores exigências legais para se constituírem.

Alves et al. (2011) encontraram essa mesma tendência em pesquisa realizada nos territórios da cidadania de Minas Gerais e da Bahia, quando $81,6 \%$ dos respondentes disseram que o tipo de organização que mais contribuía em volumes de produtos eram as associações. No mesmo sentido, Dias et al. (2013) em estudo sobre o PAA no Sertão do Apodi, no Rio Grande do Norte, observaram a predominância das associações nos 14 municípios analisados.

Portanto, os resultados apresentados no estudo refletem a realidade da gestão de projetos do PAA-DS no âmbito das associações do estado de Minas Gerais.

Com relação ao cumprimento dos projetos de PAA-DS dentro do prazo estipulado de 10 meses, pôde-se constatar que apenas 32,5\% dos respondentes disseram que as organizações que eles representaram conseguiram cumprir tal prazo.

No que se refere ao uso de um software específico para o gerenciamento de projetos, 29,9\% dos entrevistados relataram que as associações representadas por eles possuíam tal ferramenta gerencial. ${ }^{11}$

Entre as organizações sociais que utilizaram um programa de computador de SIG para o gerenciamento dos projetos, $46 \%$ cumpriram esses últimos no prazo estipulado. Em contrapartida, a taxa de cumprimento dos projetos entre as organizações sociais que não utilizaram tal instrumento foi de $25 \%$. Tais números apresentam indícios de que o uso de software de SIG para o gerenciamento de projetos do PAA-DS pode aumentar as chances de cumpri-los no prazo, como foi ilustrado por Cirino et al. (2014). Além disso, tais resultados vão ao encontro de diversos estudos sobre SIG em várias áreas e setores, ${ }^{12}$ os quais relatam que esse último aumenta a eficiência e/ou eficácia nos procedimentos de gestão, de produção e tomada de decisão, uma vez que a falta de um controle central das informações torna os processos mais suscetíveis a falhas e erros.

Outro aspecto que pode contribuir para a não execução do projeto no prazo de 10 meses é o atraso na entrega dos alimentos pelos agricultores familiares. No estudo, $39,3 \%$ das organizações sociais apresentaram esse tipo de ocorrência e $59 \%$ não, sendo que 1,7\% não respondeu tal questão.

Os atrasos na entrega dos produtos podem ser eliminados com a elaboração de um plano de produção conjunto entre as organizações sociais

11. A porcentagem de $29,9 \%$ refere-se às organizações sociais que possuíam um programa específico para o gerenciamento de projetos, enquanto que a porcentagem de $22 \%$ citada na subseção anterior, diz respeito àquelas organizações que têm tal programa como a principal ferramenta para a gestão de projetos do PAA-DS.

12. Como exemplos têm-se Cintra et al. (2012), em estudo sobre o impacto da implementação de SIG na gestão hospitalar, e De Paula, Mattedi e Silva (2012), em estudo que analisou o uso do SIG em empresas do setor metal-mecânico. 
e os agricultores familiares. Dentre os respondentes, $76,9 \%$ disseram que as organizações sociais nas quais ele estavam vinculados, elaboraram um planejamento de produção conjuntamente com os produtores, enquanto $21,4 \%$ não elaboraram, sendo que 1,7\% não respondeu a questão.

Dentre as organizações sociais que elaboraram um plano de produção, 36,7\% apresentaram algum tipo de atraso na entrega dos alimentos por parte dos agricultores familiar. Por outro lado, com relação às entidades que não realizaram um planejamento da produção, o percentual de atrasos foi de $48 \%$. Tal resultado dá indícios de uma possível correlação negativa entre a realização de um plano de produção e a incidência de atrasos na entrega dos alimentos pelos produtores que podem ser reforçados pelo fato de que, dentre as organizações que não realizaram tal plano, $8 \%$ conseguiram cumprir os prazos do projeto, enquanto que $40 \%$ das entidades que o fizeram cumpriram tais prazos. Isso vai ao encontro de Educoop (2013), segundo a qual o planejamento em conjunto das associações com os agricultores familiares é capaz de aumentar as chances de sucesso do projeto. Segundo Grisa et al. (2010), existe dificuldade por parte dos agricultores de organizar, planejar e fornecer produtos com a qualidade exigida pelo programa. Desta forma, torna-se fundamental o apoio das organizações sociais na forma de elaboração do plano de produção e do fornecimento de assistência técnica.

Segundo Educoop (2013), é essencial a figura de uma pessoa encarregada de gerir o projeto do PAA-DS. Isso porque esse último exige inúmeras contrapartidas das organizações participantes desde o momento no qual as mesmas se inscrevem no edital até o final do projeto, quando ocorre a prestação de contas. Dessa forma, faz-se necessária a presença de um gestor que deve conhecer as etapas de elaboração e execução, desde a sua concepção até o encerramento. Nesse sentido, com a existência de um gestor com experiência em projetos de PAA-DS e participação ativa na elaboração e administração das atividades a serem realizadas dentro da organização, é de se esperar que essas consigam maior êxito no cumprimento nos prazos do projeto.

A partir disso, foi perguntado sobre o número de projeto de PAA-DS que os gestores haviam participado da gestão e o número de projetos que os mesmos participaram da elaboração. Dentre os respondentes, $25,6 \%$ disseram ter participado da elaboração de um projeto, 22,2\% participaram de dois projetos, $20,5 \%$, de três projetos, $12 \%$, de quatro projetos e $18,9 \%$ participaram de cinco ou mais projetos, além de $0,9 \%$, que não respondeu. Com relação ao gerenciamento dos projetos, 35\% disseram ter participado da gestão de um projeto, $20,5 \%$ participaram de dois projetos, $15,3 \%$ geriram três projetos, $12 \%$, quatro projetos e 15,3\% participaram de cinco ou mais projetos, sendo que 1,7\% não respondeu a questão.

Em seguida, procurou-se relacionar o número de projetos que o gestor da organização participou da elaboração e o número de projetos do qual o mesmo geriu com o cumprimento do prazo dos projetos de PAA-DS. Em relação ao primeiro caso, os gestores que participaram da elaboração de apenas um projeto tiveram uma taxa de cumprimento dos prazos de $30 \%$, enquanto os que participaram da elaboração de cinco ou mais projetos apresentaram taxa de sucesso de 40,9\%, ficando os percentuais de cumprimento dos prazos para os que responderam dois, três e quatro projetos, em respectivamente, 33,3\%, 36,4\% e $30,8 \%$. Já quanto ao número de projetos geridos pelos gestores e a porcentagem de organizações que cumpriram os prazos, a taxa de sucesso entre os grupos que realizaram um, dois, três, quatro e cinco ou mais projetos foram de, respectivamente, $34,1 \%, 22,7 \%, 53,3 \%, 21,4 \%$ e $44,4 \%$. Dessa forma, aparentemente não se observa uma relação clara e uniforme entre o cumprimento dos prazos do projeto pelas organizações sociais e o número de projetos elaborados e geridos pelos respondentes.

Com relação à distribuição das organizações participantes do PAA-DS nas regiões do estado de Minas Gerais, constata-se que 39,3\% estão localizadas no norte de Minas, no Vale do Jequitinhonha e Vale do Mucuri, $15,4 \%$ no Vale 
do Rio Doce, $12 \%$ estão localizadas nas regiões metropolitana e central de Minas, $12 \%$, na Zona da Mata, 10,2\%, nas regióes sul e sudoeste de Minas e 10,2\% estão espalhadas nas demais localidades de Minas Gerais. Dentre as regióes citadas, as taxas de sucesso no cumprimento do projeto foram de, respectivamente, $34,8 \%, 27,7 \%$, $14,3 \%, 64,3 \%, 16,7 \%$ e $33,3 \%$.

Ainda sobre as regiões do estado de Minas Gerais, é importante apontar duas justificativas para se analisar o possível impacto da localização da organização social sobre a probabilidade de cumprimento do prazo de projetos do PAA-DS. A primeira é o fato de que a incidência do programa no estado não é uniforme para as regiões, conforme já discutido na Figura 2. Já a segunda decorre da reconhecida heterogeneidade dentre as mesorregiões de Minas Gerais, tanto em termos da participação das suas atividades econômicas no Produto Interno Bruto do estado quanto das suas condições econômicas e sociais, conforme destacado por Oliveira e Siqueira (2010).

\subsection{Determinantes para o cumprimento do prazo de projetos do PAA-DS por parte das organizações proponentes em Minas Gerais}

Nesta seção procura-se confirmar estatisticamente a existência ou não de relação entre o cumprimento do prazo de projetos do PAA-DS e algumas variáveis sugeridas quando da análise descritiva. Para tanto, a Tabela 1 apresenta os resultados da estimação do modelo proposto na equação 5 .

Iniciando pelas qualidades estatísticas do modelo ${ }^{13}$, observou-se que a estatística $(-46,22)$ do teste de razão de verossimilhança, cuja hipótese nula é que todos os parâmetros da equação (5) são iguais a zero, é estatisticamente significativa a 5\% (valor-p $=0,0175)$. Dessa forma, existe de fato uma regressão entre as variáveis consideradas e a probabilidade de cumprimento, por parte

13. A apresentação e a realização dos testes e análises estatísticas do modelo foram baseadas em Fávero et al. (2014). das organizações proponentes, dos projetos do PAA-DS no prazo estipulado. No mesmo sentido, das seis variáveis explicativas consideradas ${ }^{14}$, cinco foram significativas considerando nível de significância de pelo menos $10 \%$.

Em relação ao poder de previsão, verificou-se que o modelo apresentou resultado satisfatório, uma vez que $79 \%$ de suas previsões estavam corretas. Considerando apenas as previsões de respostas positivas e negativas para o cumprimento do prazo de projetos do PAA-DS, tal valor foi de, respectivamente, $70 \%$ e $84 \%$.

Ainda sobre a análise estatística do modelo, tem-se que a curva Receiver Operating Characteristic (ROC) é uma medida da capacidade do modelo em discriminar as categorias da variável dependente. Como no estudo a área sob essa curva foi de 0,8604 , o modelo utilizado tem poder discriminatório excelente, ou seja, ele separa adequadamente as organizações sociais que cumprem os projetos do PAA-DS daquelas que não cumprem.

Passando para a análise do papel de cada variável explicativa sobre a probabilidade de interesse, foram utilizados, além do efeito marginal, as razões de chances. Conforme Fávero et al. (2014), a razão de chance de uma variável indica a alteração na chance de ocorrência do evento de interesse ao se variar em uma unidade esta mesma variável (variáveis contínuas) ou em função da presença de determinada qualidade (variáveis binárias), mantidas as demais variáveis constantes.

Começando pelas variáveis de localização da organização proponente, verificou-se que elas não foram significativas. Dessa forma, pode-se concluir que não há relação entre a mesorregião mineira na qual a organização social está localizada e o cumprimento do prazo dos projetos do PAA-DS.

Em relação ao uso de um programa de computador de SIG para o gerenciamento dos

14. Considerando-se as cinco dummies regionais como uma variável única que procura verificar o impacto da localização geográfica da organização social na probabilidade de cumprimento dos projetos do PAA-DS no prazo estipulado. 
Tabela 1. Determinantes para o cumprimento do prazo de projetos de PAA-DS pelas organizações sociais no estado de Minas Gerais, 2009-2011

\begin{tabular}{lccccc}
\hline \multicolumn{1}{c}{ Variável } & Coeficiente & $\begin{array}{c}\text { Razóes de } \\
\text { Chance }\end{array}$ & Teste-Z & P-Valor & $\begin{array}{c}\text { Efeito Marginal } \\
\text { (em pontos percentuais) }\end{array}$ \\
\hline Intercepto & $-2,39$ & - & $-1,90$ & 0,057 & - \\
Soft & 1,33 & 3,7843 & 2,29 & 0,022 & 0,1916 \\
Atraso & $-2,20$ & 0,1112 & $-3,24$ & 0,001 & $-0,3162$ \\
Elab & 0,60 & 1,8177 & 1,91 & 0,056 & 0,0860 \\
Gestão & $-0,62$ & 0,5390 & $-1,98$ & 0,048 & $-0,0890$ \\
Planejamento & 2,15 & 8,5815 & 1,72 & 0,086 & 0,3095 \\
DM1 & 0,59 & - & 0,84 & 0,402 & - \\
DM2 & $-0,52$ & - & $-0,65$ & 0,517 & - \\
DM3 & $-1,14$ & - & $-1,04$ & 0,300 & - \\
DM4 & 0,86 & - & 0,93 & 0,354 & - \\
DM5 & $-0,81$ & - & $-0,55$ & 0,579 & - \\
\hline
\end{tabular}

Número de observações: 105 , com $(\mathrm{Y}=1)=35$ e $(\mathrm{Y}=0)=70$.

Nota: Devido à ausência, em alguns casos, de informação do respondente para as variáveis utilizadas, o número de observações total da amostra coletada, que era de 117, foi reduzido para 105 quando da estimação do modelo econométrico.

Fonte: Resultados da pesquisa.

projetos do PAA-DS medido pela variável explicativa Soft, verificou-se que as organizações sociais que utilizaram tal procedimento apresentaram probabilidade de cumprimento do prazo desses projetos 19,16 pontos percentuais superior em relação àquelas que não possuem tal software. Em termos de razão de chances, as organizações proponentes com a referida ferramenta gerencial aumentaram em 3,78 vezes a chance do cumprimento do projeto do PAA-DS no prazo estipulado. Dessa forma, os resultados econométricos confirmam a existência de uma relação direta entre o uso de software de SIG para o gerenciamento de projetos do PAA-DS e o cumprimento do prazo desses últimos, conforme levantado na análise descritiva. Tal relação vão ao encontro de estudos tais como Cirino et al. (2014), Alves et al. (2011) e Ghizelini (2010), os quais ressaltam a necessidade de melhorar os métodos de gerenciamento e operacionalização do PAA, uma vez que esses são apontados como as principais deficiências das organizações proponentes em relação ao acesso ao PAA. Tais deficiências poderiam ser dirimidas por meio de SIG que englobasse todas as etapas de gestão do PAA-DS, evitando a fragmentação do processo que dificulta a prestação de contas e gera atrasos no recebimento dos recursos, desestimulando os agricultores familiares envolvidos.
Dessa forma, em termos de PODC, o SIG é importante pois melhora a função administrativa organização ao definir e esquematizar todas as rotinas e procedimentos para a gestão dos projetos; a função direção, pois, ao sistematizar todo o processo de gestão referente ao projeto do PAA-DS, o SIG contribui para a execução das ações necessárias para o cumprimento de tais projetos, estimulando todos os envolvido no processo, e a função controle, pois, uma vez concentrados no SIG todas as informações e procedimentos referentes à gestão do projeto do PAA-DS, torna-se possível analisar e avaliar os resultados que estão sendo alcançados pelo grupo de maneira sistemática.

Com relação à variável Atraso, verificou-se que a ocorrência de atrasos na entrega dos produtos por parte dos agricultores familiares diminuiu a probabilidade das entidades de cumprirem o prazo do projeto do PAA-DS em 31,62 pontos percentuais. Analisando a razão de chance, tal atraso multiplica por 0,1112 a chance do cumprimento do prazo do referido projeto. Sobre esse ponto, Rocha, Cerqueira e Coelho (2007) colocam que há descompasso entre os prazos do projeto e a produção, o que poderia justificar o atraso por parte dos agricultores. No mesmo sentido, Grisa et al. (2011) argumentam que os agriculto- 
res têm dificuldades para planejarem e organizarem a sua produção visando o atendimento da quantidade e qualidade exigida pelo PAA. Essa observação vai ao encontro da importância do planejamento da produção junto aos agricultores familiares para o cumprimento do prazo da proposta de projetos do PAA-DS.

Destaca-se que os resultados do estudo, assim como já apontado quando da análise descritiva, corroboram a importância citada, uma vez que a variável Planejamento, a qual indica se a organização social realizou um plano de produção em conjunto com os agricultores familiares, aumentou a probabilidade de cumprimento do prazo de projetos do PAA-DS em 30,95 pontos percentuais, ou em 8,58 vezes, conforme razão de chances. Em termos de PODC, tal resultado ressalta a relevância da função planejamento no contexto da gestão de projetos do PAA-DS.

Por fim, quanto às variáveis explicativas referentes ao número de projetos que o responsável pela gestão dentro da organização social participou da gestão e da elaboração, representadas, respectivamente, por Gestão e Elab, elas apresentaram resultados divergentes. Enquanto o aumento do número de projetos do PAA-DS que o respondente participou da elaboração elevou em 8,60 pontos percentuais a probabilidade de uma organização cumprir o prazo de tal projeto (em termos de razão de chances, aumento de 1,82 vez as chances de cumprimento do prazo), maior número de projetos do PAA-DS que o respondente participou da gestão reduziu em 8,90 pontos percentuais a referida probabilidade (em termos de razão de chances, tal variável multiplica por 0,54 vez a chance do cumprimento do prazo do referido projeto).

No caso da variável Elab, quanto maior a participação do responsável na elaboração de projetos do PAA-DS, maior a possibilidade de o mesmo adequar o referido empreendimento à realidade e às características das organizações sociais representadas por ele, o que pode colaborar para o cumprimento de tais projetos no prazo. Já para a variável Gestão, uma possível explicação para ela apresentar sinal negativo deve-se ao fato de que maior número de projetos gerenciados talvez possa indicar acúmulo de funções para o responsável, fazendo com que o mesmo não tenha condições de disponibilizar maior tempo para acompanhar de perto as etapas do projeto. Dessa forma, a maior experiência na gestão de tais projetos por ter trabalhado em maior número deles poderia ser suplantada pelo fato de o respondente estar sobrecarregado com a gestão de vários empreendimentos simultaneamente.

\section{Conclusões}

Este trabalho buscou identificar alguns determinantes que afetaram o cumprimento dos prazos de projetos do PAA-DS pelas organizações sociais em Minas Gerais entre 2009 e 2011. Como a maioria dos elementos da amostra foi referente às associações, os resultados e discussão aplicam-se, sobretudo, para tais organizações.

Um primeiro ponto a destacar é que não se verificou diferenças no cumprimento do referido prazo entre as mesorregiões do estado, indicando que a localização geográfica da associação não influencia no processo, a despeito da heterogeneidade econômica e social existente entre elas.

Quanto à eficiência das organizações sociais no sentido de conseguiram cumprir o projeto vinculado ao PAA-DS dentro do prazo estipulado pela Conab, teve-se que mais de $60 \%$ das organizações pesquisadas não atenderam tal prazo, demonstrando ineficiência de gestão por parte delas. Um dos motivos reside na inexistência de um software de SIG que reúna em uma ferramenta gerencial todas as etapas de gestão dos projetos do PAA-DS. Apenas $30 \%$ por cento das organizações proponentes possuem tal programa, o qual aumenta em cerca de 19 pontos percentuais a probabilidade de cumprimento de tais projetos no prazo estipulado. Destaca-se que o SIG evita que o processo de gestão desses últimos torne-se fragmentado, sendo que esse problema dificulta a prestação de contas e gera atrasos no recebimento dos recursos, desestimulando os agricultores familiares envolvidos. 
Outro ponto determinante para o não cumprimento dos prazos de projetos do PAA-DS foi a ocorrência de atrasos na entrega dos produtos por parte dos agricultores familiares. Uma possível solução para esse problema é o planejamento de produção junto aos agricultores, uma vez que, quando é feito, a probabilidade de o empreendimento do PAA-DS terminar no prazo aumenta em 31 pontos percentuais.

Tanto a utilização de um SIG quanto a realização de plano de produção junto ao agricultor estão de acordo com as funções administrativas de planejamento, organização, direção e controle, indicando que a prática dessas últimas adaptada à realidade da associação é importante para o sucesso dos empreendimentos de tais organizações, incluindo projetos vinculados ao PAA-DS.

Apesar das potencialidades do PAA-DS em termos de fortalecimento da agricultura familiar, é imprescindível que tal política seja complementada por ações do governo no sentido de apoiar as organizações sociais responsáveis pelos projetos na obtenção de infraestrutura adequada e recursos suficientes para a gestão dessas propostas. Nesse sentido, mais especificamente no que tange ao PAA-DS, observou-se que a maioria dos entrevistados reconheceu a importância de se investir em um SIG capaz de condensar todas as informações necessárias para a gestão e prestação de contas desses projetos.

Entretanto, devido à falta de recursos financeiros das organizações para esse investimento, coloca-se a necessidade de políticas públicas de fomento para aquisição e implementação de tal sistema. Dessa forma, ao contribuir para a redução dos atrasos na prestação de contas de projetos do PAA-DS, tais políticas estariam contribuindo para o fortalecimento da agricultura familiar através da geração de emprego e renda no campo, que é um dos objetivos de tal programa. No mesmo sentido, políticas públicas de capacitação das organizações proponentes no sentido de permitir que as mesmas implementem a prática das funções administrativas devem ser incentivadas, uma vez que elas também contribuem para o cumprimento do prazo de projetos do PAA-DS.

\section{Referências}

ALMEIDA, L. M. M. C., FERRANTE, V. L. S. B. e PAULILLO, L. F. Rede de segurança alimentar de forte coesão social, a partir do Programa de Aquisição de Alimentos (PAA) no município de Araraquara - SP. Organizações Rurais \& Agroindustriais, v. 12, n. 3, p. 370385, set./dez. 2010.

ALVES, V. O. et al. O Associativismo na agricultura familiar dos Estados da Bahia e Minas Gerais: potencialidades e desafios frente ao Programa de Aquisição de Alimentos (PAA). Revista Administração Pública e Gestão Social, v. 3, n. 1, p. 66-88, jan./mar. 2011.

ANDRADE JÚNIOR, R. C. O programa de aquisição de alimentos da agricultura familiar (PAA) no planalto norte do estado de Santa Catarina: o caso da cooperativa agropecuária regional de pequenos produtores de Mafra (COOARPA). Cadernos do CEOM, v. 22, n. 30, p. 83-100, jun. 2009.

ARAUJO, C. A. L., TOLENTINO, M. A. e THEÓPHILO, C. R. Realidade organizacional das associações comunitárias rurais da região sul de Montes Claros, MG. In: ENCONTRO DA ASSOCIAÇÃO NACIONAL DE PÓS-GRADUAÇÃO E PESQUISA EM ADMINISTRAÇÃO (EnANPAD), 33., 2009, São Paulo. Anais... Rio de Janeiro: Anpad, 2009.

BEBBINGTON, A., ABRAMOVAY, R. e CHIRIBOGA, M. Social movements and the dynamics of rural territorial development in Latin America. World Development, v. 36, n. 12, p. 2874-2887, dez. 2008.

BIEKART, K. Seven thesis on Latin American social movements and political change: a tribute to Andre Gunder Frank (1929-2005). European Review of Latin American and Caribbean Studies, v. 79, p. 85-94, out. 2005.

BRASIL. Lei no 11.326, de 24 de julho de 2006. Estabelece as diretrizes para a formulação da Política Nacional da Agricultura Familiar e Empreendimentos Familiares Rurais. Diário Oficial [da República Federativa do Brasil], 25 jul. 2006. Seção 1. Disponível em: <http:// www.jusbrasil.com.br/topicos/10864058/lei-n-11326de-24-de-julho-de-2006>. Acesso em: set. 2013.

BUAINAIN, A. M. Agricultura familiar, agroecologia e desenvolvimento sustentável: questões para debate. Brasília: IICA, 2006.

CAMERON, A. C. e TRIVEDI, P. K. Microeconometrics: methods and applications. Cambridge: Cambridge University Press, 2005.

CINTRA, R. F. et al. Impacto da implantação de um sistema de informação gerencial na gestão de contratos 
264 - Determinantes para Cumprimento do Prazo de Projetos do Programa de Aquisição Alimentos - Doação Simultânea em Minas Gerais

públicos: o caso do hospital universitário de Dourados/ MS. Revista de Administração da Unimep, v. 10, n. 2, p. 28-53, maio/ago. 2012.

CIRINO, J. F. et al. Gerenciamento de Projetos Vinculados ao Programa de Aquisição de Alimentos Doação Simultânea em Minas Gerais. REGE - Revista de Gestão, v. 21, n. 4, p. 487-506, out./dez. 2014.

- et al. Dificuldades das organizações sociais para a gestão de Projetos do PAA-DS em Minas Gerais, 2009-2011. Sociedade e Desenvolvimento Rural, v. 9, n. 3, p. 47-72, out./dez. 2015.

et al. Estratégias de consolidação do PAA Doação Simultânea: mapeando seu gerenciamento e difundindo seus resultados. Relatório de Pesquisa. Viçosa, 2013.

CONAB - Companhia Nacional de Abastecimento. Manual de Operações Conab. Disponível em: <http:// www.conab.gov.br/conabweb/moc.php >. Acesso em: out. 2015.

Mapas PAA. Disponível em: <http://www. conab.gov.br/conteudos.php? $\mathrm{a}=1406 \& \mathrm{t}=2>$. Acesso em: mar. 2013.

DE PAUlA, J., MATTEDI, A. P. e DA SILVA, E. R. S. Sistemas de informação nas empresas de Itajubá. 9o CONTECSI - International Conference on Information Systems and Technology Management, v. 9, n. 1, p. 186207, maio/jun. 2012.

DIAS, T. F. et al. Programa de Aquisição de Alimentos da Agricultura Familiar (PAA) como estratégia de inserção socioeconômica: o caso do Território da Cidadania Sertão do Apodi (RN). Revista Brasileira de Gestão e Desenvolvimento Regional, v. 9, n. 3, set./dez. 2013.

EDUCOOP - Associação dos Educadores Cooperativistas do Brasil. PAA Doação Simultânea - Gestão do projeto. Disponível em: <http:// cursoscooperativistas.com.br/portal/moodle $>$. Acesso em: mar. 2013.

FAVERO, L. P. et al. Métodos quantitativos com Stata. Rio de Janeiro: Campus-Elsevier, 2014.

GHIZELINI, A. A. M. Atores sociais, agricultura familiar camponesa e o espaço local: uma análise a partir do programa de aquisição de alimentos. 2010. Tese (Doutorado em Sociologia) - Universidade Federal do Paraná, Setor de Ciências Humanas, Letras e Artes, Curitiba, 2010.

GRISA, C. et al. O Programa de Aquisição de Alimentos (PAA) em perspectiva: apontamentos e questões para o debate. Retratos de Assentamentos, n. 13, p. 137-170, 2010.
Contribuições do Programa de Aquisição de Alimentos à segurança alimentar e nutricional e à criação de mercados para a agricultura familiar. Agriculturas, v. 8, n. 3, p. 34-41, set. 2011.

GUJARATI, D. M.; PORTER, D. C. Basic econometrics. 5. ed. Columbus, Ohio: McGraw-Hill, 2008.

IBGE - Instituto Brasileiro de Geografia e Estatística. Censo Agropecuário 2006 - Agricultura Familiar: primeiros resultados. Brasil, Grandes Regiões e Unidades da Federação. Rio de Janeiro: IBGE, 2009.

. Mapas IBGE. Disponível em: < http://mapas. ibge.gov.br>. Acesso em: mar. 2013.

LACOMBE, F. e HEILBORN, G. Administração: princípios e tendências. 2. ed. São Paulo: Saraiva, 2008.

LANDAU, E. C. et al. Variação geográfica do tamanho dos módulos fiscais no Brasil. Sete Lagoas: Embrapa Milho e Sorgo, 2012.

MAGALHÃES, A. M. e SOARES, A. Os impactos do PAA-Leite sobre o preço, a produção e a renda da pecuária leiteira In: VAITSMAN, J. e PAES-SOUSA, R. (Orgs.). Avaliação de Políticas e Programas. Vol. 1. Brasília: MDS - Ministério do Desenvolvimento Social e Combate à Fome, 2007, p. 143-198.

MDS - Ministério do Desenvolvimento Social e Combate à Fome. Programa de Aquisição de Alimentos (PAA). Disponível em: <http://mds.gov.br/assuntos/ seguranca-alimentar/programa-de-aquisicao-dealimentos-paa>. Acesso em: out. 2015.

OLIVEIRA, L.A.S. Politicas Públicas e estratégia sustentável de combate à fome: o caso do PAA-Leite no município de Quixeramobim, Ceará. 2011. 91 f. Dissertação (Mestrado em Economia Rural) - Universidade Federal do Ceará, Fortaleza, 2011.

OLIVEIRA, D. P. R. Sistemas de Informações Gerenciais: estratégicas, táticas, operacionais. 13. ed. São Paulo: Atlas, 2009.

OLIVEIRA, F. A. e SIQUEIRA, W. B. (Orgs.). As muitas Minas: ensaios sobre a economia mineira. Belo Horizonte: Conselho Regional de Economia, Minas Gerais, 2010.

PMI - Project Management Institute. Guide to the project management body of knowledge, PMBOK Guide. 5. ed. Newtown Square, Pennsylvania: PMI, 2013.

REARDON, T., BERDEGUÉ, J. e ESCOBAR, G. Rural nonfarm employment and incomes in Latin America: overview and policy implications. World Development, v. 29, n. 3, p. 395-410, mar. 2001. 
ROCHA, A. G. P., CERQUEIRA, P. S. e COELHO, V. P. Um panorama do Programa de Aquisição de Alimentos no Estado da Bahia: estudos de caso em Boa Vista do Tupim, Tapiramutá e Vitória da Conquista. Sociedade e Desenvolvimento Rural, v. 1, n. 1, jul./dez. 2007.

SANTOS, A. R. et al. Agricultura familiar e segurança alimentar e nutricional: análise dos resultados do Programa de Aquisição de Alimentos (PAA Doação Simultânea) nos Estados da Bahia e Minas Gerais. Cadernos Gestão Social, v. 3, n. 1, p. 9-24, jan.jun. 2012.

SILVA, J. G. Local sustainable development, globalization and agricultural restructuring in underdeveloped countries. International Journal of Sociology of Agriculture and Food, v. 10, n. 1, p. 33-39, fev. 2002.
SOBREIRA, D. B. Avaliação dos impactos do Programa de Aquisição de Alimentos (PAA) no estado do Ceará: o caso do mel. 2014. 160 f. Dissertação (Mestrado em Economia Rural) - Universidade Federal do Ceará, Fortaleza, 2014.

TENÓRIO, F. G. Flexibilização organizacional, mito ou realidade? Rio de Janeiro: FGV, 2000.

VIEIRA, D. F. A. e GROSSI, M. E. D. Influência do Programa de Aquisição de Alimentos na comercialização dos produtos da agricultura familiar: o caso do município de Paracatu em Minas Gerais. Sociedade e Desenvolvimento Rural, v. 4, n. 2, maio/ago. 2010.

WOOLDRIDGE, J. M. Introdução à econometria: uma abordagem moderna. São Paulo: Thomson Pioneira, 2011. 
